\title{
Synthesis of Hydrotalcite from Bittern, and Its Removal Abilities of Phosphate and Nitrate
}

\author{
Takaaki Wajima
}

\begin{abstract}
In this study, hydrotalcite was synthesized from bittern solution with addition of $\mathrm{AlCl}_{3}(\mathrm{Mg} / \mathrm{Al}$ molar ratio of the solution $=3$ ), and its removal abilities of phosphate and nitrate from aqueous solution were examined. Hydrotalcite can be synthesized from bittern and seawater, and the product from bittern is higher content of hydrotalcite than that from seawater. The product from bittern has a removal abilities of phosphate and nitrate, which were higher than commercial hydrotalcite. The equilibrium adsorption capacity of the product for phosphate and nitrate ions were measured and extrapolated using Langmuir and Freundlich isotherm models, and experimental data are found to fit Langmuir than Freundlich. In the solution with $1 \mathrm{mM}$ of phosphate or nitrate ions, adsorption of phosphate on the product was saturated within $30 \mathrm{~min}$ and almost constant after $30 \mathrm{~min}$, while that of nitrate increase within $15 \mathrm{~min}$ and then gradually decrease, due to the ion exchange reaction of chlorine and sulphate in the product.
\end{abstract}

Index Terms-Hydrotalcite, bittern, removal of phosphorus and nitrate, anion exchange.

\section{INTRODUCTION}

The hydrotalcite (HT) is classified as a layered double hydroxide (LDH) composed of metal complex hydroxide: $\left[\mathrm{M}^{2+}{ }_{1-x} \mathrm{M}^{3+}{ }_{x}(\mathrm{OH})_{2}\right]^{x+}\left[\left(\mathrm{A}^{n-}\right)_{x / n} n n \mathrm{H}_{2} \mathrm{O}\right]^{x_{-}}(x=0.2-0.33)$, where $\mathrm{M}^{2+}$ and $\mathrm{M}^{3+}$ are divalent and trivalent metal ions, respectively, and $\mathrm{A}^{n-}$ is anionic species [1]. The structure of HTs consists of a positive charged brucite-like octahedral layer and a negatively charged interlayer containing anions and water molecules [2]. The positively charged layer is formed by partial substitution of a trivalent metal for a divalent one. The layers can be stacked, and the balancing interlayer anions can be exchanged with other anions.

HT have received increasing attention in recent years as ion-exchanger [3]-[8], catalyst [9], [10], precursor for catalyst [11]-[13] and antacids [14]-[16] in medical application. Extensive studies have been made on the method of preparation and the physicochemical properties of HT compounds [17]-[21].

Eutrophication is a water enrichment in nutrients that generally leads to symptomatic changes when the production of algae and other aquatic vegetations are increased, degradation of fisheries and deterioration of water quality as

Manuscript received August 9, 2014; revised November 12, 2014. This work was supported by the Cooperative Research Program of the Institute of Ocean Energy, Saga University (14004A).

Takaaki Wajima is with Department of Urban Environment Systems, Graduate School of Engineering, Chiba University, Japan (e-mail: wajima@tu.chiba-u.ac.jp). well as all its uses in general. Eutrophication is a peculiar form of water pollution, causing major alterations: abnormal water colorations, loss of transparency and toxicity by the presence of certain algae products [22]. The eutrophication process is caused by the increase in nutrients levels, particularly phosphorus and nitrogen, which exceeds the limiting threshold of the primary production and, consequently, ecosystem control mechanisms are not used [23]. In order to prevent eutrophication, it is considered to reduce the load of phosphorus and nitrate to water environment. One method is the removal of phosphate and nitrate ion by HT [24]-[28]. However, HT is an expensive material used as antacid, etc., and it is necessary to develop a new process for inexpensive HT.

The bittern was the by-product from the refinement process of salt. Though the bitterns are regarded as waste material, several kinds of ions $\left(\mathrm{Mg}^{2+}, \mathrm{Ca}^{2+}, \mathrm{K}^{+}, \mathrm{Na}^{+}\right)$are rich in bittern. Especially, magnesium ion is the most abundant cation species in bittern.

In this study, HT was synthesized using bittern in consideration for the utilization of plant-producing $\mathrm{Mg}(\mathrm{OH})_{2}$, and the characteristics of removal for phosphate and nitrate by the HT was examined for the application of water purification.

\section{MATERIALS AND METHODS}

\section{A. Seawater and Bittern}

Seawater and two bittern samples were used in this study. Seawater was collected from the surface layer of Imari bay, Saga prefecture, Japan. Two bittern was obtained from two Japanese salt making plants with different processes. Chemical compositions and $\mathrm{pHs}$ of these samples are shown in Table I. The contents of $\mathrm{Na}^{+}, \mathrm{K}^{+}, \mathrm{Mg}^{2+}, \mathrm{Ca}^{2+}, \mathrm{Cl}^{-}, \mathrm{Br}^{-}$and $\mathrm{SO}_{4}{ }^{2-}$ in samples were determined by ion chromatography (DX-120, Dionex), and $\mathrm{pHs}$ of the sample were measured by pH meter (MA-130, Mettler toledo).

TABLE I: CHEMICAL COMPOSITIONS AND PHS OF SEAWATER AND BITTERNS

\begin{tabular}{ccccc}
\hline & Seawater & Bittern-1 & Bittern-2 \\
\hline Contents $(\mathrm{g} / \mathrm{L})$ & & & \\
$\mathrm{Na}^{+}$ & 9.7 & 103.5 & 30.7 \\
$\mathrm{~K}^{+}$ & 0.4 & 5.4 & 35.0 \\
$\mathrm{Mg}^{2+}$ & 1.3 & 14.8 & 43.9 \\
$\mathrm{Ca}^{2+}$ & 0.4 & N.D. & 24.6 \\
$\mathrm{Cl}^{-}$ & 18.5 & 204.1 & 250.8 \\
$\mathrm{Br}^{-}$ & N.D. & N.D. & 18.3 \\
$\mathrm{SO}_{4}{ }^{2-}$ & 4.4 & 43.0 & N.D. \\
\hline $\mathrm{pH}^{2}$ & 7.7 & 7.4 & 6.8 \\
\hline \hline
\end{tabular}




\section{B. Synthesis of Hydrotalcite}

$1 \mathrm{M} \mathrm{AlCl}_{3}$ solution was added to $100 \mathrm{~mL}$ of seawater or bittern to adjust the $\mathrm{Mg} / \mathrm{Al}$ molar ratio of 3 in the mixed solution, and stirred at $50{ }^{\circ} \mathrm{C}$ for $24 \mathrm{~h}$. During stirring, $\mathrm{pH}$ of the solution was maintained at 10.5 by dropping $10 \mathrm{w} / \mathrm{v} \%$ $\mathrm{NaOH}$ solution. After stirring, precipitates were filtered, washed with distilled water, and then dried at $80{ }^{\circ} \mathrm{C}$ to obtain the product. The products were identified using X-ray diffraction (XRD) (RINT-2500, Rigaku), and was observed by scanning electron microscope (SEM) (S-2400, Hitachi). To determine chemical composition of the products, $25 \mathrm{mg}$ of the product was perfectly dissolved in $10 \mathrm{~mL}$ of $0.1 \mathrm{M} \mathrm{HNO}_{3}$ solution, the contents of $\mathrm{Mg}^{2+}$ and $\mathrm{Al}^{3+}$ were measured by inductively-coupled plasma spectrometers (ICP-AES) (SPS3000, Seiko instruments), and those of $\mathrm{Cl}^{-}$and $\mathrm{SO}_{4}{ }^{2-}$ were determined using ion chromatograph. The content of $\mathrm{CO}_{3}$ in the product was analyzed by carbon/sulfur analyzer (EMIA1200, Horiba). Differential thermal analysis (DTA) / thermogravimetry (TG) (TG8120, Rigaku) was carried out in the temperature range $20-800{ }^{\circ} \mathrm{C}$ at a heating rate of $10{ }^{\circ} \mathrm{C}$ $\min ^{-1}$ in flowing air.

\section{Removal Tests of Phosphate and Nitrate}

Isotherm experiments of removals for phosphate and nitrate using the product from bittern-1 were performed as follows: $0.1 \mathrm{~g}$ of the product was added to $20 \mathrm{~mL}$ of the solution of $\mathrm{NaH}_{2} \mathrm{PO}_{4}$ or $\mathrm{NaNO}_{3}$ with $1-25 \mathrm{mM}$ in $50 \mathrm{~mL}$ of centrifuge tube, and the slurry was shaken with reciprocal shaker for $12 \mathrm{~h}$. After shaking, the tube was centrifuged, and the concentrations of phosphate and nitrate in supernatant were measured using ion chromatograph.

The adsorption amounts of phosphate and nitrate per sample were calculated using the following equation;

$$
q=\left(C_{0}-C\right) \bullet V / w
$$

where $C_{0}$ and $C$ are the initial and final concentrations of phosphate and nitrate in the solution $(\mathrm{mmol} / \mathrm{L})$, respectively, $V$ is the solution volume (L), and $w$ is the mass of sample added to the solution $(\mathrm{g})$.

Kinetics of removal reaction for phosphate and nitrate using the product were determined as follows; $50 \mathrm{mg}$ of the product was added to $100 \mathrm{~mL}$ of the solution of $\mathrm{NaH}_{2} \mathrm{PO}_{4}$ or $\mathrm{NaNO}_{3}$ with $1 \mathrm{mM}$ in $200 \mathrm{~mL}$ baker, and the slurry was stirred with magnetic stirrer for $120 \mathrm{~min}$. During stirring, $2 \mathrm{~mL}$ of aliquot was removed, and then filtered to obtain the filtrate, and the concentrations of phosphate, nitrate, chloride and sulfate in the filtrate were measured using ion chromatograph.

\section{RESULTS AND DisCUSSION}

Fig. 1 shows XRD diffraction patterns of the products from (a) bittern-1, (b) bittern-2 and (c) seawater. It is clear that from Fig. 1 that the HT can be formed as a main reaction product with addition of $\mathrm{AlCl}_{3}$. The single peak pattern of HT is identified in both products from bitterns, while the product from seawater is the mixture of HT, calcite and brucite. The order of peak intensities for HT is the product from bittern-1 > that from bittern-2 > that from seawater.

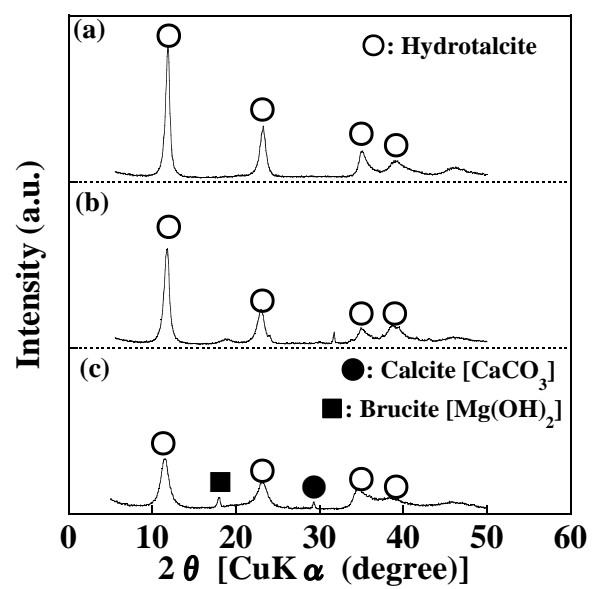

Fig. 1. X-ray diffraction patterns of the products from (a) bittern-1, (b) bittern-2 and (c) seawater.

Table II shows chemical compositions of the products and commercial hydrotalcite. As the HT has positive charged sites based on the $\mathrm{Al}^{3+}$ in double hydroxide layer [21], the intercalated amount of anion should be theoretically equal to the $\mathrm{Al}^{3+}$ amount in the HT. Namely, the amount of $\mathrm{Al}^{3+}$ should be in accord with the anion exchange capacity of the HT. The anion exchange capacities of the products were estimated to be $2.7-2.8 \mathrm{mmol} / \mathrm{g}$, and that of commercial HT are also considered to be $2.0 \mathrm{mmol} / \mathrm{g}$. Generally speaking, $1 \mathrm{mmol} / \mathrm{g}$ or more of anion exchange capacity should be required as a standard for the practical use. So these exchange capacities may be adequate large as an anion exchanger.

The amount of exchangeable anions in commercial HT is $2.1 \mathrm{mmol} / \mathrm{g}$ as $\mathrm{CO}_{3}$, which is almost same as anion exchange capacity of commercial HT (2.0 mmol/g). It is considered that exchangeable anion in $\mathrm{HT}$ present as monovalent $\mathrm{HCO}_{3}{ }^{-}$. The exchangeable anions in the products are mainly $\mathrm{Cl}^{-}, \mathrm{SO}_{4}{ }^{2-}$ and $\mathrm{HCO}_{3}^{-}$, and the total amounts of exchangeable anions are 2.9 $\mathrm{mmol} / \mathrm{g}$ in the product from bttern- 1 and $3.0 \mathrm{mmol} / \mathrm{g}$ in the product from bittern-2, respectively, which are almost same as anion exchange capacities of the products. Therefore, these three anions are mainly exchangeable anions in the product. It is noted that the product from seawater is low content of $\mathrm{Cl}$ and high content of $\mathrm{CO}_{3}$, due to the present of calcite in the product.

The $\mathrm{Mg} / \mathrm{Al}$ molar ratios of the products indicate 3.5 - 3.6, and they may be higher than 3.0 of the set value in the HT preparation. It may be caused by the nature of the solution with different concentration of $\mathrm{Mg}^{2+}$ and some coexisting ions. It is noted that $\mathrm{Mg} / \mathrm{Al}$ molar ratio of commercial HT is 4.4 .

TABLE II: CHEMICAL COMPOSITIONS OF THE PRODUCTS AND COMMERCIAL HYDROTALCITE

\begin{tabular}{|c|c|c|c|c|c|c|}
\hline & \multicolumn{5}{|c|}{ Chemical composition (mmol/g) } & \multirow{2}{*}{$\begin{array}{c}\mathrm{Mg} / \mathrm{Al} \\
\text { molar } \\
\text { ratio }\end{array}$} \\
\hline & $\mathrm{Mg}$ & $\mathrm{Al}$ & $\mathrm{Cl}$ & $\mathrm{SO}_{4}$ & $\mathrm{CO}_{3}$ & \\
\hline The product from bittern-1 & 9.8 & 2.8 & 1.6 & 0.3 & 0.7 & 3.5 \\
\hline The product from bittern- 2 & 9.4 & 2.7 & 1.9 & 0.1 & 0.9 & 3.6 \\
\hline The product from seawater & 8.3 & 2.8 & 0.1 & 0.4 & 2.2 & 3.0 \\
\hline Commercial HT & 8.7 & 2.0 & & & 2.1 & 4.4 \\
\hline
\end{tabular}

The DTA and TG curves of the product from bittern-1 are shown in Fig. 2. The DTA curve shows two endothermic peaks at 210 and $370^{\circ} \mathrm{C}$. Corresponding to these peaks, the TG curve shows two step mass losses of 11.1 mass\% by 
$230^{\circ} \mathrm{C}$ and 18.0 mass $\%$ between 350 and $400^{\circ} \mathrm{C}$. The first step, around $210{ }^{\circ} \mathrm{C}$, with a weight loss of $11.1 \%$ is due to the loss of physically adsorbed and interlayer water molecules. The second step, around $370{ }^{\circ} \mathrm{C}$, with sum weight losses of $18.0 \%$ can be ascribed to the dehydroxyration of structural water (hydroxyl group in the brucite-like layer) and the elimination of anions $\left(\mathrm{Cl}^{-}\right.$and $\left.\mathrm{CO}_{3}{ }^{2-}\right)$. These reactions give rise to the destruction of the layered structure to form calcined hydrotalcite. These curves of the product resemble that given for hydrotalcite-like compounds in the literature [29], [30]. This suggests the nature of bittern has little effect on the final structure and thus thermal degradation of the HT.

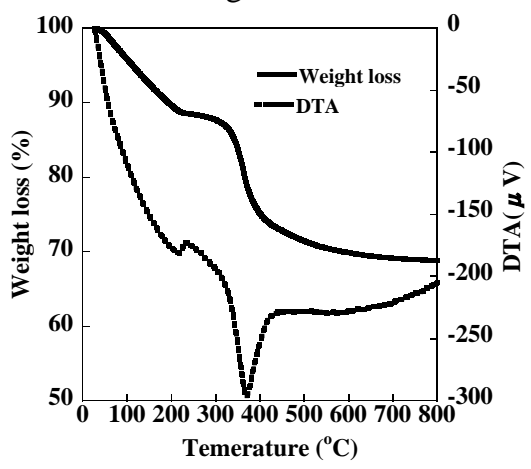

Fig. 2.TG-DTA curves of the product from bittern-1.

Fig. 3 illustrates the SEM photograph of the product. The particles of the product have smooth surface, and consists of an aggregate of primary particles.

The removal isotherms of (a) phosphate and (b) nitrate using the product and commercial HT are shown in Fig. 4. With increasing equilibrium concentration, the adsorptions of phosphate and nitrate increase to approximately $0.6 \mathrm{mmol} / \mathrm{g}$ and $0.4 \mathrm{mmol} / \mathrm{g}$, respectively, and both becomes almost constant, while the adsorption of commercial HT for phosphate and nitrate are $0.18 \mathrm{mmol} / \mathrm{g}$ and zero, respectively. The product has better adsorption capacities of phosphate and nitrate than commercial HT.
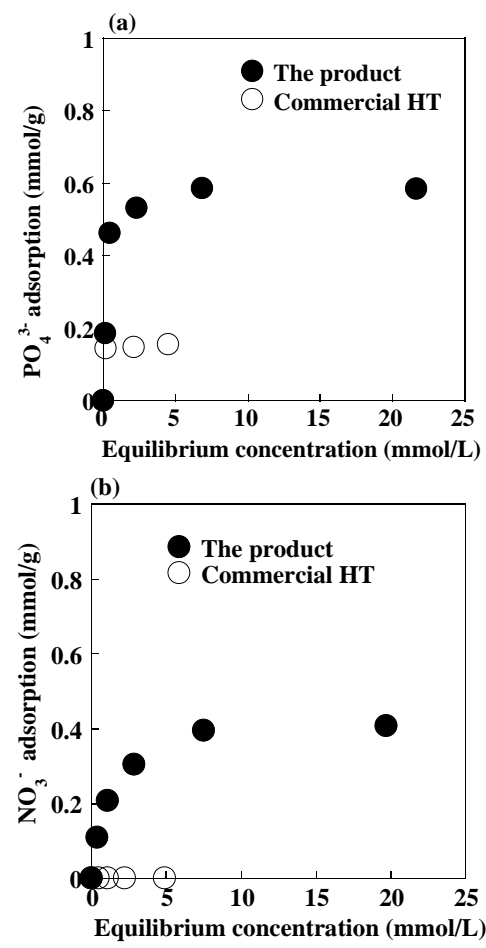

Fig. 4. Isotherm for adsorption of (a) phosphate and (b) nitrate using the product and commercial HT.

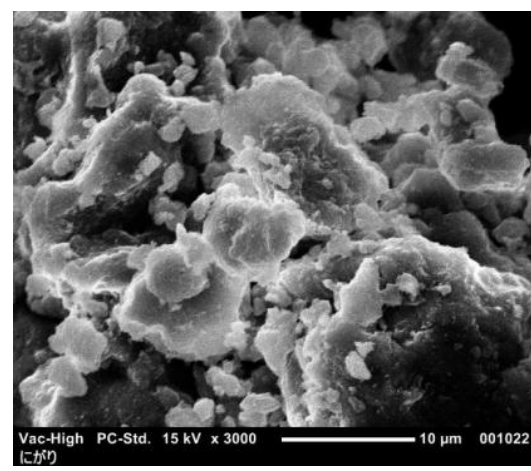

Fig. 3. SEM photograph of the product from bittern-1.

The removal behaviors of the product for phosphate and nitrate are determined by the isotherm models. Several isotherm models are available to describe the equilibrium sorption distribution with the Langmuir and Freundlich models being commonly used to fit experimental data. The linear forms of the Langmuir and Freundlich models are given by:

$$
\begin{gathered}
C_{e} / q_{e}=1 /\left(Q_{\max } \bullet K_{L}\right)+C_{e} / Q_{\max } \\
\ln \left(q_{e}\right)=\ln \left(K_{F}\right)+(1 / n) \bullet \ln \left(C_{e}\right)
\end{gathered}
$$

where $q_{e}$ is the amount of phosphate or nitrate adsorbed at equilibrium $(\mathrm{mmol} / \mathrm{g}) ; Q_{\max }(\mathrm{mmol} / \mathrm{g})$ and $K_{L}(\mathrm{~L} / \mathrm{mg})$ are Langmuir constants related to the maximum adsorption capacity corresponding to complete coverage of available adsorption sites and a measure of adsorption energy (equilibrium adsorption constant), respectively. $K_{F}$ and $n$ are Freundlich constants.

The values of Langumuir and Freundlich constants and regression coefficients for phosphate and nitrate removal were given in Table III. For both phosphate and nitrate, the correlation regression coefficients $\left(R^{2}\right)$ of Langmuir model indicate a better fitting than the Freundlich model, and the maximum adsorption capacity of the product for $\mathrm{PO}_{4}{ }^{3-}$ and $\mathrm{NO}_{3}{ }^{-}$calculated from Langmuir model is $0.59 \mathrm{mmol} / \mathrm{g}$ and $0.43 \mathrm{mmol} / \mathrm{g}$, respectively.

TABLE III: ISOTHERM PARAMETERS FOR ADSORPTION OF POHSPHATE AND NITRATE ON THE PRODUCT

\begin{tabular}{ccccccc}
\hline \hline & \multicolumn{3}{c}{ Langmuir } & \multicolumn{3}{c}{ Freundlich } \\
\cline { 2 - 7 } & $Q_{\max }$ & $K_{L}$ & $R^{2}$ & $n$ & $K_{F}$ & $R^{2}$ \\
\hline Phosphate & 0.59 & 5.14 & 1.000 & 5.04 & 0.39 & 0.691 \\
Nitrate & 0.43 & 0.93 & 0.999 & 2.99 & 0.18 & 0.901 \\
\hline \hline
\end{tabular}

The removals of phosphate and nitrate during the reaction and the release of chloride and sulfate from the product are shown in Fig. 5. In the case of phosphate (Fig. 5 (a)), the removal of phosphate increases rapidly and reaches an equilibrium value within $20 \mathrm{~min}$, while the release of chloride into the solution increases and reaches equilibrium value within $20 \mathrm{~min}$ and that of sulphate are always zero, which means that phosphate in the solution can be rapidly removed by ion exchange reaction of chloride in the product. In the case of nitrate (Fig. 5 (b)), the removal of nitrate increases rapidly within $10 \mathrm{~min}$ and gradually decreases after $20 \mathrm{~min}$, while the releases of chloride and sulphate into the solution increases and reaches equilibrium value within $10 \mathrm{~min}$. In first stage by $20 \mathrm{~min}$, nitrate in the solution can be rapidly removed by ion exchange reaction of chloride and sulphate in the 
product, but in the second stage, the nitrate in the product released into the solution by ion exchange, such as $\mathrm{CO}_{3}{ }^{2-}$, because the uptake of monovalent nitrate ion by HT is weaker than that of divalent ion.
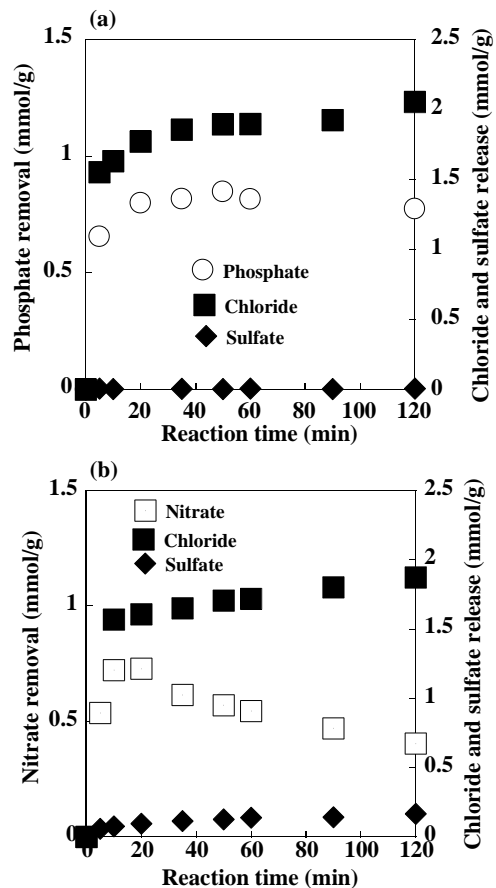

Fig. 5. The removal of (a) phosphate and (b) nitrate during the reaction and the release of chloride and sulfate from the product.

\section{ACKNOWLEDGMENT}

This work was supported by the Cooperative Research Program of the Institute of Ocean Energy, Saga University (14004A).

\section{REFERENCES}

[1] T. Kwon, G. A. Tsigdinos, and T. J. Pinnavaia, "Pillaring of layered double hydroxides (LDH's) by polyoxometalate anions," J. Am. Chem. Soc., vol. 110, pp. 3653-3654, 1988.

[2] S. Miyata, "The syntheses of hydrotalcite-like compounds and their structures and physico-chemical properties $\mathrm{I}$ : The systems $\mathrm{Mg}^{2+}-\mathrm{Al}^{3+}-\mathrm{NO}_{3}{ }^{-}, \mathrm{Mg}^{2+}-\mathrm{Al}^{3+}-\mathrm{Cl}^{-}, \mathrm{Mg}^{2+}-\mathrm{Al}^{3+}-\mathrm{ClO}_{4}{ }^{-}, \mathrm{Ni}^{2+}-\mathrm{Al}^{3+}-\mathrm{Cl}^{-}$and $\mathrm{Zn}^{2+}-\mathrm{Al}^{3+}-\mathrm{Cl}^{-}$," Clays Clay Miner., vol. 23, pp. 369-375, 1975.

[3] S. Miyata, "Physico-chemical properties of synthetic hydrotalcites in relation to composition," Clays Clay Miner., vol. 28, pp. 50-56, 1980

[4] S. Miyata, "Anion-exchange properties of hydrotalcite-like compounds," Clays Clay Miner., vol. 31, pp. 305-311, 1983.

[5] A. Schutz and P. Biloen, "Interlamellar chemistry of hydrotalcites: I. Polymerization of silicate anions," J. Solid State Chem., vol. 68, pp. 360-368, 1987.

[6] H. Kopka, K. Beneke, and G. Lagaly, "Anionic surfactants between double metal hydroxide layers," J. Colloid Interface Sci., vol. 123, pp. 427-436, 1988.

[7] K. Chibwe and W. Jones, "Intercalation of organic and inorganic anions into layered double hydroxides," J. Chem. Soc. Chem. Com. vol. 14, pp. 926-927, 1989.

[8] E. Narita, T. Yamagishi, and K. Suzuki, "Adsorption property of aromatic sulfonate ions by heat-treated layered double hydroxides," Nippon Kagaku Kaishi, pp. 676-679, 1992.

[9] K. J. Martin and T. J. Pinnavaia, "Layered double hydroxides as supported anionic reagents. Halide-ion reactivity in zinc chromium hexahydroxide halide hydrates $\left[\mathrm{Zn}_{2} \mathrm{Cr}(\mathrm{OH})_{6} \mathrm{X}_{\mathrm{nH}} \mathrm{O}\right](\mathrm{X}=\mathrm{Cl}, \mathrm{I})$, , $J$. Am. Chem. Soc., vol. 108, pp. 541-542, 1986.

[10] E. Suzuki, M. Okamoto, and Y. Ono, "Catalysis by interlayer anions of a synthetic hydrotalcite-like mineral in a halide exchange between organic halides," Chem. Lett., vol. 18, pp. 1485-1486, 1989.

[11] H. Schaper, J. J. Berg-Slot, and W. H. J. Stork, "Stabilized magnesia: A novel catalyst (support) material," Appl. Catal., vol. 54, pp. 79-80, 1989.
[12] O. Clause, M. Gazzano, F. Trifiró, A. Vaccari, and L. Zatorski, "Preparation and thermal reactivity of nickel/chromium and nickel/aluminium hydrotalcite-type precursors," Appl. Catal., vol. 73, pp. 217-236, 1991.

[13] O. Clause, B. Rebours, E. Merlen, F. Trifiró, and A. Vaccari, "Preparation and characterization of nickel-aluminum mixed oxides obtained by thermal decomposition of hydrotalcite-type precursors," $J$. Catal., vol. 133, pp. 231-246, 1992.

[14] A. C. Playle, S. R. Gunning, and A. F. Llewellyn, "The in vitro antacid and anti-pepsin activity of hydrotalcite," Pharm. Acta Helv., vol. 49, pp. 298-302, 1974.

[15] F. Cavani, F. Trifiró, and A Vaccari, "Hydrotalcite-type anionic clays: preparation, properties and applications," Catal. Today, vol. 11, pp. 173-301, 1991.

[16] P. Parashar, V. Sharma, D. D. Agrwal, and N. Richhariya, "Rapid synthesis of hydrotalcite with high antacid activity," Mater. Lett., vol. 74, pp. 93-95, 2012.

[17] M. Lal and A. T. Howe, "Studies of zinc-chromium hydroxy salts. I. Thermal decomposition of $\left[\mathrm{Zn}_{2} \mathrm{Cr}(\mathrm{OH})_{6}\right] \mathrm{X} \cdot \mathrm{nH}_{2} \mathrm{O}$, where $\mathrm{X}^{-}=\mathrm{F}^{-}, \mathrm{Cl}^{-}$, $\mathrm{Br}^{-}, \mathrm{I}^{-}, 1 / 2 \mathrm{CO}_{3}{ }^{2-}$ and $\mathrm{NO}_{3}{ }^{-}$, ' J. Solid State Chem., vol. 39, pp. 368-376, 1981.

[18] C. J. Sarnna, J. L. Rendon, and J. E. Iglesias, "Crystal-Chemical Study of Layered $\left[\mathrm{Al}_{2} \mathrm{Li}(\mathrm{OH})_{6}\right]^{+} \mathrm{X}^{-} \cdot \mathrm{nH}_{2} \mathrm{O}$," Clays Clay Miner., vol. 30, pp. 180-184, 1982.

[19] I. Pausch, H. H. Lohse, K. Schürmann, and R. Allmann, "Syntheses of Disordered and Al-rich Hydrotalcite-Like Compounds," Clays Clay Miner., vol. 34, pp. 507-510, 1986.

[20] T. Kameda, T. Yoshioka, M. Uchida, and A. Okuwaki, "Hydrotalcite synthesis using calcined dolomite as a magnesium and alkali source," $J$. Mater. Sci. Lett., vol. 21, pp. 1747-1749, 2002.

[21] N. Murayama, I. Maekawa, H. Ushiro, and T. Miyoshi, "Synthesis of various layered double hydroxides using aluminum dross generated in aluminum recycling process," Int. J. Miner. Process., vol. 110-111, pp. 46-52, 2012.

[22] C. S. Reynolds, "Ecology of phytoplankton," New York: Cambridge University Press, 2006.

[23] A. A. Ansari, S. S. Gill, G. R. Lanza, and W. Rast, "Eutrophication: Causes, Consequences and Control," New York: Springer, 2010.

[24] A. Kawamoto, A. Ookubo, T. Sato, and T. Suzuki, "Phosphorus removal from wastewater by layer structure inorganic ion exchanger with high selectivity for phosphate anion," Mizukankyougakkaishi, vol. 22, pp. 875-881, 1999.

[25] H. Shin, M. Kim, S. Nam, and H. Moon, "Phosphorus removal by hydrotalcite-like compounds (HTLcs)," Water Sci. Technol., vol. 34, pp. 161-168, 1996.

[26] K. Hosni and E. Srasra, "Nitrate adsorption from aqueous solution by $\mathrm{M}^{\mathrm{II}}$-Al- $\mathrm{CO}_{3}$ layered double hydroxide," Inorg. Mater., vol. 44, pp. 742-749, 2008.

[27] A. Halajnia, S. Oustan, N. Najafi, A. R. Khataee, and A. Lakzian, "The adsorption characteristics of nitrate on $\mathrm{Mg}-\mathrm{Fe}$ and $\mathrm{Mg}-\mathrm{Al}$ layered double hydroxides in a simulated soil solution," Appl. Clay Sci., vol. 70, pp. 28-36, 2012.

[28] A. Halajnia, S. Oustan, N. Najafi, A. R. Khataee, and A. Lakzian, "Adsorption-desorption characteristics of nitrate, phosphate and sulfate on Mg-Al layered double hydroxide," Appl. Clay Sci., vol. 80-81, pp. 305-312, 2013.

[29] T. Hibino, Y. Yamashita, K. Kosuge, and A. Tsunashima, "Decarbonation behavior of $\mathrm{Mg}-\mathrm{Al}-\mathrm{CO}_{3}$ hydrotalcite-like compounds during heat-treatment," Clays Clay Miner., vol. 43, pp. 427-432, 1995.

[30] E. Narita, "Intercalation property and application of layered double hydroxide," Nendokagaku, vol. 46, pp. 207-218, 2007.

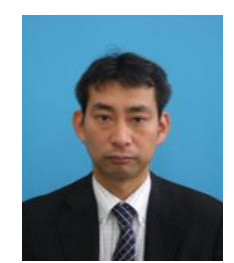

Takaaki Wajima was born in February, 1976 in Saga Prefecture, Japan. He has been an associate professor in the Department of Urban Environment Systems, Graduate School of Engineering, Chiba University, Japan, since 2013. He received his bachelor's degree and master's degree in resource engineering from Kyoto University, Japan in 1998 and 2000, respectively, and doctor of philosophy (Ph.D.) degree in environmental mineralogy and technology from Kyoto University, Japan in 2004. His main research theme was "Micro-porous Materials Synthesized from Paper Sludge Ash at Low Temperature, and its Chemical Mineralogy." In 2004, he moved to the Institute of Ocean Energy in Saga University as a postdoctoral researcher, and from 2007 to 2013 he was an assistant professor at Akita University, Japan. His main research interests are waste recycling, resource recovery, and environmental purification. 